\title{
DESIGN AND SYNTHESIS OF NOVEL 1-((DIMETHYLAMINO)METHYL)-3-(4-(3-(SUBSTITUTE DPHENYL)-4-OXOTHIAZOLIDIN-2-YL)PHENYLIMINO)-5-NITROINDOLIN-2-ONES AS POTENT ANTITUBERCULAR AGENTS
}

\author{
KOSARAJU LAHARI ${ }^{1,2}$, RAJA SUNDARARAJAN ${ }^{2 *}$ \\ ${ }^{1}$ Department of Pharmaceutical Chemistry, MNR College of Pharmacy, Fasalwadi, Sangareddy, Telangana, India. ${ }^{2}$ Department of \\ Pharmaceutical Chemistry, GITAM Institute of Pharmacy, GITAM University, Visakhapatnam, Andhra Pradesh, India. \\ Email: sraja61@gmail.com
}

Received: 10 January 2019, Revised and Accepted: 05 April 2019

ABSTRACT

Objective: Isatins have emerged as antimicrobial agents due to their broad spectrum of in vitro and in vivo antimicrobial activities. In addition, thiazolidinone also reported to possess various biological activities particularly antimicrobial activity. Due to the importance, we planned to synthesize compounds with isatin functionality coupled with thiazolidinone as possible antitubercular and antimicrobial agents which could furnish better therapeutic results.

Methods: In vitro Mycobacterium tuberculosis method and agar streak dilution test are used to estimate antitubercular and antimicrobial potency of title analogs, respectively. Minimum inhibitory concentration of entire title compounds was determined against all tested microorganism such as M. tuberculosis, four Gram-positive, three Gram-negative bacteria, and two fungi.

Results: A series of new thiazolidinone substituted Schiff and Mannich bases of 5-nitroisatins were designed and synthesized by a multistep synthesis from isatin. Structures of synthesized compounds are characterized using Fourier-transform infrared, proton nuclear magnetic resonance, mass spectroscopy, and bases of elemental analysis. Mild to good antitubercular and antimicrobial activity was showed by synthesized 5-nitroisatin analogs. The relationship between the biological activity and the functional group variation of the tested compounds was discussed.

Conclusion: 3-(4-(3-(4-Aminophenyl)-4-oxothiazolidin-2-yl)phenylimino)-1-((dimethyl amino)methyl)-5-nitroindolin-2-one 6 and 3-(4-(3(2-aminophenyl)-4-oxothiazolidin-2-yl)phenylimino)-1-((dimethylamino)methyl)-5-nitroindolin-2-one 13 were found to be the most potent compounds of this series which might be extended as a novel class of antimicrobial agents.

Keywords: 5-Nitroisatin, Indole-2,3-dione, Schiff base, Mannich base, Antitubercular activity, Antimicrobial activity.

(c) 2019 The Authors. Published by Innovare Academic Sciences Pvt Ltd. This is an open access article under the CC BY license (http://creativecommons. org/licenses/by/4. 0/) DOI: http://dx.doi.org/10.22159/ajpcr.2019.v12i5.31965

\section{INTRODUCTION}

Bacteria Mycobacterium tuberculosis is the causative organism for tuberculosis (TB). In general, a lung is a major part affected by TB, but other parts can also be affected by TB. Globally within diseases caused by single infectious agent TB is the second largest killer. According to the WHO, every year about 9 million people are affected by TB. Among them, 3 million people are missed by current health systems. TB is one of the top three reasons for the death of women aged between 15 and 44 . TB is an airborne disease and is two types, i.e., latent TB and active TB [1]. Chronic cough with sputum containing blood, weight loss, fever, and night sweats is the characteristic symptoms of active TB. It is believed that about one-third of the world's population has latent TB. Latent TB becoming active only in $10 \%$ cases, but the risk is much higher in people who have compromised immune systems, i.e., people living with HIV or malnutrition, or people who smoke [2].

Serious life-threatening adverse effect of available antitubercular drugs (anorexia, asthenia, depression, neuritis, hepatotoxicity, etc.) and development of resistance are the two common problems associated with TB treatment $[3,4]$. In addition, around the world, the emergence and increase of multidrug-resistant(MDR) and extensively drug resistant (XDR) strains of M. tuberculosis have been alarming authorities. High mortality rates and low cure rates are the two major difficulties faced in the treatment due to these strains $[5,6]$. Furthermore, in the clinic, drug-resistant TB cases are also reported $[7,8]$. Hence, a priority task is the development of new drugs with activity against MDR-TB, XDR-TB, and XDR-TB. Moreover, new agents that will shorten the duration of current chemotherapy are also needed. To tackle the menace, there is a need to search for newer therapeutic agents [9].

Majority of the currently available medicinal compounds consist of one or more heterocyclic ring system. From the contemporary medicinal chemistry investigation, it was found that isatin is one such significant heterocyclic system which has been gained magnitude due to the broad array of biological activities [10-18]. Isatins have emerged as antimicrobial agents due to their broad spectrum of in vitro and in vivo antimicrobial activities [19-27]. In addition, thiazolidinone also reported to possess various biological activities particularly antimicrobial activity [28-32]. Due to the importance, we planned to synthesize compounds with isatin functionality coupled with thiazolidinone as possible antitubercular and antimicrobial agents which could furnish better therapeutic results. Based on these findings, with the hope to obtain more active and less toxic antimicrobial agents, we decided to synthesize a new series of 1-((dimethylamino)methyl)-3-(4-(3-(substitutedphenyl)-4oxothiazolidin-2-yl)phenyl imino)-5-nitroindolin-2-ones and evaluated its antitubercular and antimicrobial activities.

\section{MATERIALS AND METHODS}

Materials

The chemicals and reagents used were obtained from various chemical units Qualigens, E. Merck India Ltd., CDH, and SD Fine Chem. These solvents used were of LR grade and purified before their use. The silica 
gel G used for analytical chromatography (tthin-layer chromatography [TLC]) was obtained from E. Merck India Ltd. All the melting points were taken in open glass capillary and are uncorrected. Proton nuclear magnetic resonance $\left({ }^{1} \mathrm{H}-\mathrm{NMR}\right)$ spectra were recorded at $500 \mathrm{MHz}$ on Bruker Avance-500 NMR spectrometer in $\mathrm{CDCl}_{3}$ using tetramethylsilane as an internal standard. The chemical shifts are reported in ppm scale. Mass spectra were obtained on a JEOL-SX-102 instrument using electron impact ionization. All the IR spectra were recorded in $\mathrm{KBr}$ pellets on a Jasco Fourier-transform infrared (FT-IR) 410 spectrometer. Elemental analyses were performed on a Perkin Elmer model 2400C analyzer and were within $\pm 0.4 \%$ of the theoretical values.

\section{Preparation of 5-nitroisatin (2)}

According to the reported literature, the 5-nitroisatin 2 was prepared [33]. In $500 \mathrm{ml}$ round-bottomed flask (RBF), $0.33 \mathrm{~mol}$ of isatin ( $48.5 \mathrm{~g}$ ) was added slowly to a mixture of $0.5 \mathrm{~mol}$ conc. nitric acid ( $35 \mathrm{ml} / 50 \mathrm{~g}$ ) and $0.75 \mathrm{~mol}$ conc. sulfuric acid $(40 \mathrm{ml} / 74 \mathrm{~g}$ ) with frequent shaking. In crushed ice cold water, the flask was immersed and cooled. After adding all isatin, at $60^{\circ} \mathrm{C}$, the contents of the RBF were refluxed in water for the period of $1 \mathrm{~h}$. Later in a beaker containing $500 \mathrm{ml}$ cold water, the refluxed mixture was transferred and stirred to remove excess acid present. At the bottom, 5-nitroisatin 2 was settled down completely and the acidic upper layer was removed by decantation. Then in separating funnel, the residual bottom layer was transferred, $50 \mathrm{ml}$ of water was added to it and shaken vigorously. Finally, to obtain pure 5-nitroisatin 2 the residual layer was collected, filtered, and dried with anhydrous calcium chloride. Yield $=68 \%$, m.p. $230-232^{\circ} \mathrm{C}$. IR $(\mathrm{KBr}) \mathrm{cm}^{-1}$ : 3349 (NH), 3025 (Ar-CH), 1731 (C=0), 1613 (C=C), 1546 and $1328\left(\mathrm{NO}_{2}\right) .{ }^{1} \mathrm{H}-\mathrm{NMR}\left(\mathrm{CDCl}_{3}, 500 \mathrm{MHz}\right) \delta \mathrm{ppm}: 7.19-7.62(\mathrm{~m}, 3 \mathrm{H}$, Ar-CH), 9.16 (s, 1H, NH of isatin). EI-MS m/z: $192\left(\mathrm{M}^{+}\right)$. Anal. Calcd for $\mathrm{C}_{8} \mathrm{H}_{4} \mathrm{~N}_{2} \mathrm{O}_{4}: \mathrm{C}, 50.01 ; \mathrm{H}, 2.10 ; \mathrm{N}, 14.58$. Found: C, 50.19; H, 2.09; N, 14.53 .

\section{Preparation of 4-(5-nitro-2-oxoindolin-3-ylideneamino)} benzaldehyde (3)

$0.1 \mathrm{Mol}$ of 5-nitro isatin 2 (19.2 g) and $0.1 \mathrm{~mol}$ of $p$-amino benzaldehyde $(12.1 \mathrm{~g})$ were dissolved in warm ethanol $(150 \mathrm{ml})$ containing catalytic quantities of glacial acetic acid $(5 \mathrm{ml})$. At $100^{\circ} \mathrm{C}$, the contents were refluxed in a water bath for the period of $4 \mathrm{~h}$ and set aside for $1 \mathrm{~h}$. The resultant product 4-(5-nitro-2-oxoindolin-3-ylideneamino)benzaldehyde three was collected, filtered, washed with ethanol, and dried. Yield $=74 \%$, m.p. $197-199^{\circ} \mathrm{C}$. IR (KBr) cm${ }^{-1}$ : $3371(\mathrm{NH}), 3018(\mathrm{Ar}-\mathrm{CH}), 1720$ (C=0), $1669(\mathrm{C}=\mathrm{N}), 1604(\mathrm{C}=\mathrm{C}), 1522$ and $1335\left(\mathrm{NO}_{2}\right) \cdot{ }^{1} \mathrm{H}-\mathrm{NMR}\left(\mathrm{CDCl}_{3}, 500 \mathrm{MHz}\right)$ $\delta$ ppm: 7.25-7.91 (m, 7H, Ar-CH), 9.27 (s, 1H, NH of isatin), 10.13 (s, $1 \mathrm{H}$, CH of CHO). EI-MS m/z: $295\left(\mathrm{M}^{+}\right)$. Anal. Calcd for $\mathrm{C}_{15} \mathrm{H}_{9} \mathrm{~N}_{3} \mathrm{O}_{4}: \mathrm{C}, 61.02 ; \mathrm{H}$, 3.07; N, 14.23. Found: C, 60.87; H, 3.08; N, 14.27 .

Preparation of 4-(1-((dimethylamino)methyl)-5-nitro-2oxoindolin-3-ylideneamino) benzaldehyde (4)

To the solution of 0.05 mol 4-(5-nitro-2-oxoindolin-3-ylideneamino) benzaldehyde $3(14.75 \mathrm{~g})$ in ethanol $(100 \mathrm{ml}), 37 \%$ aqueous formaldehyde $(1.5 \mathrm{ml})$ was added. Then, $0.05 \mathrm{~mol}$ of dimethylamine (2.25 g) was added with stirring slowly to the above mixture. The entire reaction mixture was stirred after adding all dimethylamine for $5 \mathrm{~h}$ mechanically at room temperature and kept in the refrigerator for 1 day to form crystals. The obtained crystals of 4-(1-((dimethylamino) methyl)-5-nitro-2-oxoindolin-3-ylideneamino)benzaldehyde 4 were separated by filtration and dried in vacuum. To obtain pure product compound 4 was recrystallized using ethanol. Yield $=72$ m.p. 214$217^{\circ} \mathrm{C}$. IR (KBr) cm ${ }^{-1}: 3009$ ( $\left.\mathrm{Ar}-\mathrm{CH}\right), 2884\left(\mathrm{CH}_{3}-\mathrm{CH}\right), 1715(\mathrm{C}=0), 1642$ $(\mathrm{C}=\mathrm{N}), 1628(\mathrm{C}=\mathrm{C}), 1541$ and $1340\left(\mathrm{NO}_{2}\right) \cdot{ }^{1} \mathrm{H}-\mathrm{NMR}\left(\mathrm{CDCl}_{3}, 500 \mathrm{MHz}\right) \delta$ ppm: 2.17 (s, $\left.6 \mathrm{H}, \mathrm{N}\left(\mathrm{CH}_{3}\right)_{2}\right), 4.32\left(\mathrm{~s}, 2 \mathrm{H}, \mathrm{CH}_{2}\right.$ linkage), 7.04-7.85 (m, $7 \mathrm{H}$, Ar-CH), 10.22 (s, 1H, CH of CHO). EI-MS m/z: $352\left(\mathrm{M}^{+}\right)$. Anal. Calcd for $\mathrm{C}_{18} \mathrm{H}_{16} \mathrm{~N}_{4} \mathrm{O}_{4}: \mathrm{C}, 61.36 ; \mathrm{H}, 4.58 ; \mathrm{N}, 15.90$. Found: C, 61.49; H, 4.60; N, 15.85.

General procedure for synthesis of 1-((dimethylamino)methyl)-3(4-(3-(substituted phenyl)-4-oxothiazolidin-2-yl)phenylimino)-5nitroindolin-2-one (5-19)

To a mixture of $0.01 \mathrm{~mol}$ 4-(1-((dimethylamino)methyl)-5-nitro2-oxoindolin-3-ylideneamino)benzaldehyde $4(3.52$ g) and 0.01 mol various aryl amines in ethanol $(20 \mathrm{ml}) 0.01 \mathrm{~mol}$ mecaptoacetic acid $(0.92 \mathrm{~g})$ were added with stirring slowly. Latter a mixture of zinc chloride $(0.5 \mathrm{~g})$ in ethanol $(10 \mathrm{ml})$ was added with vigorous stirring slowly. The contents were refluxed in a water bath at $100^{\circ} \mathrm{C}$ for $12 \mathrm{~h}$. Then, the reaction mixture was poured into ice cold water and stirred well. The product separated 5-19 were filtered, washed with water and dried. The residue was recrystallized from ethanol.

1- ( (Dimethylamino) methyl) - 5 - nitro-3 - (4 - (4-oxo-3 phenylthiazolidin-2-yl)phenylimino) indolin-2-one (5) Yield $=75 \%$, m.p. $274-276^{\circ} \mathrm{C}$. IR (KBr) cm ${ }^{-1}: 3002(\mathrm{Ar}-\mathrm{CH}), 2937$ $\left(\mathrm{CH}_{2}-\mathrm{CH}\right), 1715(\mathrm{C}=0), 1650(\mathrm{C}=\mathrm{N}), 1623(\mathrm{C}=\mathrm{C}), 1536$ and $1348\left(\mathrm{NO}_{2}\right)$. ${ }^{1} \mathrm{H}-\mathrm{NMR}\left(\mathrm{CDCl}_{3}, 500 \mathrm{MHz}\right) \delta \mathrm{ppm}: 2.26\left(\mathrm{~s}, 6 \mathrm{H}, \mathrm{N}\left(\mathrm{CH}_{3}\right)_{2}\right), 3.64(\mathrm{~s}, 2 \mathrm{H}$, $\mathrm{CH}_{2}$ of thiazolidinone), $4.18\left(\mathrm{~s}, 2 \mathrm{H}, \mathrm{CH}_{2}\right.$ linkage), $6.07(\mathrm{~s}, 1 \mathrm{H}, \mathrm{CH}$ of thiazolidinone), 6.93-7.88 (m, 12H, Ar-CH). EI-MS m/z: $501\left(\mathrm{M}^{+}\right)$. Anal. Calcd. for $\mathrm{C}_{26} \mathrm{H}_{23} \mathrm{~N}_{5} \mathrm{O}_{4} \mathrm{~S}$ : C, 62.26; $\mathrm{H}, 4.62 ; \mathrm{N}, 13.96$. Found: $\mathrm{C}, 62.08 ; \mathrm{H}$, $4.64 ; \mathrm{N}, 14.00$

3-(4-(3-(4-Aminophenyl)-4-oxothiazolidin-2-yl)phenylimino)-1((dimethylamino)methyl) -5-nitroindolin-2-one (6)

Yield $=78 \%$, m.p. $208-210^{\circ} \mathrm{C}$. IR $(\mathrm{KBr}) \mathrm{cm}^{-1}: 3364(\mathrm{NH}), 3029(\mathrm{Ar}-\mathrm{CH})$, $2950\left(\mathrm{CH}_{2}-\mathrm{CH}\right), 1737(\mathrm{C}=0), 1673(\mathrm{C}=\mathrm{N}), 1621(\mathrm{C}=\mathrm{C}), 1548$ and 1312 $\left(\mathrm{NO}_{2}\right) .{ }^{1} \mathrm{H}-\mathrm{NMR}\left(\mathrm{CDCl}_{3}, 500 \mathrm{MHz}\right) \delta \mathrm{ppm}: 2.32\left(\mathrm{~s}, 6 \mathrm{H}, \mathrm{N}\left(\mathrm{CH}_{3}\right)_{2}\right), 3.56(\mathrm{~s}$, $2 \mathrm{H}, \mathrm{CH}_{2}$ of thiazolidinone), $4.24\left(\mathrm{~s}, 2 \mathrm{H}, \mathrm{NH}_{2}\right), 4.31\left(\mathrm{~s}, 2 \mathrm{H}, \mathrm{CH}_{2}\right.$ linkage), 6.25 (s, 1H, CH of thiazolidinone), 7.18-8.03 (m, 11H, Ar-CH). EI-MS m/z: $516\left(\mathrm{M}^{+}\right)$. Anal. Calcd. for $\mathrm{C}_{26} \mathrm{H}_{24} \mathrm{~N}_{6} \mathrm{O}_{4} \mathrm{~S}: \mathrm{C}, 60.45 ; \mathrm{H}, 4.68 ; \mathrm{N}, 16.27$. Found: $\mathrm{C}, 60.62 ; \mathrm{H}, 4.66 ; \mathrm{N}, 16.23$.

1-((Dimethylamino)methyl)-3-(4-(3-(4-hydroxyphenyl)-4oxothiazolidin-2-yl)phenyl imino)-5-nitroindolin-2-one (7) Yield $=79 \%$, m.p. $291-294^{\circ} \mathrm{C}$. IR (KBr) cm${ }^{-1}: 3652(\mathrm{OH}), 3016(\mathrm{Ar}-\mathrm{CH})$, $2941\left(\mathrm{CH}_{2}-\mathrm{CH}\right), 1734(\mathrm{C}=0), 1663(\mathrm{C}=\mathrm{N}), 1618(\mathrm{C}=\mathrm{C}), 1529$ and 1325 $\left(\mathrm{NO}_{2}\right) \cdot{ }^{1} \mathrm{H}-\mathrm{NMR}\left(\mathrm{CDCl}_{3}, 500 \mathrm{MHz}\right) \delta \mathrm{ppm}: 2.41\left(\mathrm{~s}, 6 \mathrm{H}, \mathrm{N}\left(\mathrm{CH}_{3}\right)_{2}\right), 3.47(\mathrm{~s}$, $2 \mathrm{H}, \mathrm{CH}_{2}$ of thiazolidinone), $4.29\left(\mathrm{~s}, 2 \mathrm{H}, \mathrm{CH}_{2}\right.$ linkage), $5.18(\mathrm{~s}, 1 \mathrm{H}, \mathrm{OH})$, $5.80(\mathrm{~s}, 1 \mathrm{H}, \mathrm{CH}$ of thiazolidinone), 7.04-8.16 (m, 11H, Ar-CH). EI-MS m/z: $517\left(\mathrm{M}^{+}\right)$. Anal. Calcd. for $\mathrm{C}_{26} \mathrm{H}_{23} \mathrm{~N}_{5} \mathrm{O}_{5} \mathrm{~S}: \mathrm{C}, 60.34 ; \mathrm{H}, 4.48 ; \mathrm{N}, 13.53$. Found: C, $60.50 ; \mathrm{H}, 4.49 ; \mathrm{N}, 13.48$.

1-((Dimethylamino)methyl)-3-(4-(3-(4-methoxyphenyl)-4oxothiazolidin-2-yl)phenyl imino)-5-nitroindolin-2-one (8) Yield $=82 \%$, m.p. $257-259^{\circ} \mathrm{C}$. IR $(\mathrm{KBr}) \mathrm{cm}^{-1}: 3005(\mathrm{Ar}-\mathrm{CH}), 2924\left(\mathrm{CH}_{2}-\right.$ $\mathrm{CH}), 1718(\mathrm{C}=0), 1656(\mathrm{C}=\mathrm{N}), 1627(\mathrm{C}=\mathrm{C}), 1529$ and $1350\left(\mathrm{NO}_{2}\right), 1078$ (C-O-C). ${ }^{1} \mathrm{H}-\mathrm{NMR}\left(\mathrm{CDCl}_{3}, 500 \mathrm{MHz}\right) \delta \mathrm{ppm}: 2.18\left(\mathrm{~s}, 6 \mathrm{H}, \mathrm{N}\left(\mathrm{CH}_{3}\right)_{2}\right), 3.36(\mathrm{~s}$, $2 \mathrm{H}, \mathrm{CH}_{2}$ of thiazolidinone), $3.95\left(\mathrm{~s}, 3 \mathrm{H}, \mathrm{OCH}_{3}\right), 4.19\left(\mathrm{~s}, 2 \mathrm{H}, \mathrm{CH}_{2}\right.$ linkage), 5.91 (s, 1H, CH of thiazolidinone), 7.32-8.05 (m, 11H, Ar-CH). EI-MS m/z: $531\left(\mathrm{M}^{+}\right)$. Anal. Calcd. for $\mathrm{C}_{27} \mathrm{H}_{25} \mathrm{~N}_{5} \mathrm{O}_{5} \mathrm{~S}$ : C, 61.00; H, 4.74; N, 13.17 . Found: C, 60.83; H, 4.76; N, 13.12 .

1-((Dimethylamino)methyl) - 5-nitro-3 - (4- (4-oxo-3 - ptolylthiazolidin-2-yl)phenylimino) indolin-2-one (9)

Yield $=80 \%$, m.p. $225-227^{\circ} \mathrm{C}$. IR (KBr) cm${ }^{-1}: 3024(\mathrm{Ar}-\mathrm{CH}), 2957$ $\left(\mathrm{CH}_{2}-\mathrm{CH}\right), 1729(\mathrm{C}=0), 1672(\mathrm{C}=\mathrm{N}), 1605(\mathrm{C}=\mathrm{C}), 1548$ and $1313\left(\mathrm{NO}_{2}\right)$. ${ }^{1} \mathrm{H}-\mathrm{NMR}\left(\mathrm{CDCl}_{3}, 500 \mathrm{MHz}\right) \delta \mathrm{ppm}: 2.25\left(\mathrm{~s}, 6 \mathrm{H}, \mathrm{N}\left(\mathrm{CH}_{3}\right)_{2}\right), 2.71\left(\mathrm{~s}, 3 \mathrm{H}, \mathrm{CH}_{3}\right)$, $3.58\left(\mathrm{~s}, 2 \mathrm{H}, \mathrm{CH}_{2}\right.$ of thiazolidinone), $4.04\left(\mathrm{~s}, 2 \mathrm{H}, \mathrm{CH}_{2}\right.$ linkage $), 6.17(\mathrm{~s}, 1 \mathrm{H}$, $\mathrm{CH}$ of thiazolidinone), 7.23-8.09 (m, 11H, Ar-CH). EI-MS m/z: $515\left(\mathrm{M}^{+}\right)$. Anal. Calcd. for $\mathrm{C}_{27} \mathrm{H}_{25} \mathrm{~N}_{5} \mathrm{O}_{4} \mathrm{~S}$ : C, 62.90; $\mathrm{H}, 4.89 ; \mathrm{N}, 13.58$. Found: C, 62.71; $\mathrm{H}, 4.90 ; \mathrm{N}, 13.63$.

1-((Dimethylamino)methyl)-5-nitro-3-(4-(3-(4-nitrophenyl)-4oxothiazolidin-2-yl)phenyl imino)indolin-2-one (10)

Yield $=76 \%$, m.p. $263-265^{\circ} \mathrm{C}$. IR (KBr) cm ${ }^{-1}: 3013(\mathrm{Ar}-\mathrm{CH}), 2945$ $\left(\mathrm{CH}_{2}-\mathrm{CH}\right), 1720(\mathrm{C}=0), 1664(\mathrm{C}=\mathrm{N}), 1626(\mathrm{C}=\mathrm{C}), 1551$ and $1349\left(\mathrm{NO}_{2}\right)$. ${ }^{1} \mathrm{H}-\mathrm{NMR}\left(\mathrm{CDCl}_{3}, 500 \mathrm{MHz}\right) \delta \mathrm{ppm}: 2.27\left(\mathrm{~s}, 6 \mathrm{H}, \mathrm{N}\left(\mathrm{CH}_{3}\right)_{2}\right), 3.61(\mathrm{~s}, 2 \mathrm{H}$, $\mathrm{CH}_{2}$ of thiazolidinone), $4.26\left(\mathrm{~s}, 2 \mathrm{H}, \mathrm{CH}_{2}\right.$ linkage), $6.24(\mathrm{~s}, 1 \mathrm{H}, \mathrm{CH}$ of thiazolidinone), 6.93-7.95 (m, 11H, Ar-CH). EI-MS m/z: $546\left(\mathrm{M}^{+}\right)$. Anal. Calcd. for $\mathrm{C}_{26} \mathrm{H}_{22} \mathrm{~N}_{6} \mathrm{O}_{6} \mathrm{~S}$ : C, 57.14; $\mathrm{H}, 4.06 ; \mathrm{N}, 15.38$. Found: C, 57.33; $\mathrm{H}$, 4.04; N, 15.35 . 
3-(4-(3-(4-Chlorophenyl)-4-oxothiazolidin-2-yl)phenylimino)-1((dimethylamino)methyl)-5-nitroindolin-2-one (11)

Yield $=78 \%$, m.p. $250-252^{\circ} \mathrm{C}$. IR $(\mathrm{KBr}) \mathrm{cm}^{-1}: 3005(\mathrm{Ar}-\mathrm{CH}), 2926$ $\left(\mathrm{CH}_{2}-\mathrm{CH}\right), 1732(\mathrm{C}=0), 1661(\mathrm{C}=\mathrm{N}), 1619(\mathrm{C}=\mathrm{C}), 1524$ and $1337\left(\mathrm{NO}_{2}\right)$, 785 (C-Cl). ${ }^{1} \mathrm{H}-\mathrm{NMR}\left(\mathrm{CDCl}_{3}, 500 \mathrm{MHz}\right) \delta \mathrm{ppm}: 2.18\left(\mathrm{~s}, 6 \mathrm{H}, \mathrm{N}\left(\mathrm{CH}_{3}\right)_{2}\right), 3.32$ (s, $2 \mathrm{H}, \mathrm{CH}_{2}$ of thiazolidinone), 4.15 (s, $2 \mathrm{H}, \mathrm{CH}_{2}$ linkage), 6.09 (s, $1 \mathrm{H}, \mathrm{CH}$ of thiazolidinone), 6.80-8.23 (m, 11H, Ar-CH). EI-MS m/z: $535\left(\mathrm{M}^{+}\right)$. Anal. Calcd. for $\mathrm{C}_{26} \mathrm{H}_{22} \mathrm{ClN}_{5} \mathrm{O}_{4} \mathrm{~S}$ : C, 58.26; $\mathrm{H}, 4.14 ; \mathrm{N}, 13.07$. Found: C, 58.07; $\mathrm{H}$, $4.15 ; \mathrm{N}, 13.11$.

3-(4-(3-(4-Bromophenyl)-4-oxothiazolidin-2-yl)phenylimino)-1((dimethylamino)methyl)-5-nitroindolin-2-one (12)

Yield $=79 \%$, m.p. $219-222^{\circ} \mathrm{C}$. IR (KBr) cm${ }^{-1}: 3016(\mathrm{Ar}-\mathrm{CH}), 2933\left(\mathrm{CH}_{2}{ }^{-}\right.$ $\mathrm{CH}), 1738(\mathrm{C}=\mathrm{O}), 1659(\mathrm{C}=\mathrm{N}), 1614(\mathrm{C}=\mathrm{C}), 1530$ and $1322\left(\mathrm{NO}_{2}\right), 691$ (C-Br). ${ }^{1} \mathrm{H}-\mathrm{NMR}\left(\mathrm{CDCl}_{3}, 500 \mathrm{MHz}\right) \delta \mathrm{ppm}: 2.34\left(\mathrm{~s}, 6 \mathrm{H}, \mathrm{N}\left(\mathrm{CH}_{3}\right)_{2}\right), 3.56$ (s, $2 \mathrm{H}, \mathrm{CH}_{2}$ of thiazolidinone), 4.20 (s, $2 \mathrm{H}, \mathrm{CH}_{2}$ linkage), $5.82(\mathrm{~s}, 1 \mathrm{H}, \mathrm{CH}$ of thiazolidinone), 7.19-8.27 (m, 11H, Ar-CH). EI-MS m/z: $579\left(\mathrm{M}^{+}\right)$. Anal. Calcd. for $\mathrm{C}_{26} \mathrm{H}_{22} \mathrm{BrN}_{5} \mathrm{O}_{4} \mathrm{~S}: \mathrm{C}, 53.80 ; \mathrm{H}, 3.82 ; \mathrm{N}, 12.07$. Found: $\mathrm{C}, 53.64 ; \mathrm{H}$, $3.83 ; \mathrm{N}, 12.12$

3-(4-(3-(2-Aminophenyl)-4-oxothiazolidin-2-yl)phenylimino)-1((dimethylamino)methyl)-5-nitroindolin-2-one (13)

Yield $=76 \%$, m.p. $286-288^{\circ} \mathrm{C}$. IR $(\mathrm{KBr}) \mathrm{cm}^{-1}: 3381(\mathrm{NH}), 3023(\mathrm{Ar}-\mathrm{CH})$, $2948\left(\mathrm{CH}_{2}-\mathrm{CH}\right), 1726(\mathrm{C}=0), 1650(\mathrm{C}=\mathrm{N}), 1629(\mathrm{C}=\mathrm{C}), 1535$ and 1354 $\left(\mathrm{NO}_{2}\right) .{ }^{1} \mathrm{H}-\mathrm{NMR}\left(\mathrm{CDCl}_{3}, 500 \mathrm{MHz}\right) \delta \mathrm{ppm}: 2.21\left(\mathrm{~s}, 6 \mathrm{H}, \mathrm{N}\left(\mathrm{CH}_{3}\right)_{2}\right), 3.45(\mathrm{~s}$, $2 \mathrm{H}, \mathrm{CH}_{2}$ of thiazolidinone), $4.13\left(\mathrm{~s}, 2 \mathrm{H}, \mathrm{NH}_{2}\right), 4.20\left(\mathrm{~s}, 2 \mathrm{H}, \mathrm{CH}_{2}\right.$ linkage), $5.90(\mathrm{~s}, 1 \mathrm{H}, \mathrm{CH}$ of thiazolidinone), 7.12-8.08 (m, 11H, Ar-CH). EI-MS m/z: $516\left(\mathrm{M}^{+}\right)$. Anal. Calcd. for $\mathrm{C}_{26} \mathrm{H}_{24} \mathrm{~N}_{6} \mathrm{O}_{4} \mathrm{~S}: \mathrm{C}, 60.45 ; \mathrm{H}, 4.68 ; \mathrm{N}, 16.27$. Found: C, 60.59; H, 4.67; N, 16.21 .

1-((Dimethylamino)methyl)-3-(4-(3-(2-hydroxyphenyl)-4oxothiazolidin-2-yl)phenyl imino)-5-nitroindolin-2-one (14)

Yield $=75 \%$, m.p. $294-296^{\circ} \mathrm{C}$. IR $(\mathrm{KBr}) \mathrm{cm}^{-1}: 3644(\mathrm{OH}), 3008(\mathrm{Ar}-\mathrm{CH})$, $2952\left(\mathrm{CH}_{2}-\mathrm{CH}\right), 1719(\mathrm{C}=0), 1661(\mathrm{C}=\mathrm{N}), 1603(\mathrm{C}=\mathrm{C}), 1556$ and 1347 $\left(\mathrm{NO}_{2}\right) .{ }^{1} \mathrm{H}-\mathrm{NMR}\left(\mathrm{CDCl}_{3}, 500 \mathrm{MHz}\right) \delta \mathrm{ppm}: 2.42\left(\mathrm{~s}, 6 \mathrm{H}, \mathrm{N}\left(\mathrm{CH}_{3}\right)_{2}\right), 3.40$ (s, $2 \mathrm{H}, \mathrm{CH}_{2}$ of thiazolidinone), $4.15\left(\mathrm{~s}, 2 \mathrm{H}, \mathrm{CH}_{2}\right.$ linkage), $5.36(\mathrm{~s}, 1 \mathrm{H}, \mathrm{OH})$, 6.13 (s, 1H, CH of thiazolidinone), 7.05-8.31 (m, 11H, Ar-CH). EI-MS m/z: $517\left(\mathrm{M}^{+}\right)$. Anal. Calcd. for $\mathrm{C}_{26} \mathrm{H}_{23} \mathrm{~N}_{5} \mathrm{O}_{5} \mathrm{~S}$ : C, 60.34; H, 4.48; N, 13.53 . Found: C, 60.22; H, 4.50; N, 13.56 .

1-((Dimethylamino)methyl)-3-(4-(3-(2-methoxyphenyl)-4oxothiazolidin-2-yl)phenyl imino)-5-nitroindolin-2-one (15) Yield $=77 \%$, m.p. $239-241^{\circ} \mathrm{C}$. IR (KBr) cm${ }^{-1}: 3012(\mathrm{Ar}-\mathrm{CH}), 2930\left(\mathrm{CH}_{2}^{-}\right.$ $\mathrm{CH}), 1718(\mathrm{C}=0), 1674(\mathrm{C}=\mathrm{N}), 1606(\mathrm{C}=\mathrm{C}), 1525$ and $1319\left(\mathrm{NO}_{2}\right), 1067$ (C-O-C). ${ }^{1} \mathrm{H}-\mathrm{NMR}\left(\mathrm{CDCl}_{3}, 500 \mathrm{MHz}\right) \delta \mathrm{ppm}: 2.32$ (s, 6H, N( $\left.\mathrm{CH}_{3}\right)_{2}$ ), 3.30 (s, $2 \mathrm{H}, \mathrm{CH}_{2}$ of thiazolidinone), $3.82\left(\mathrm{~s}, 3 \mathrm{H}, \mathrm{OCH}_{3}\right), 4.07\left(\mathrm{~s}, 2 \mathrm{H}, \mathrm{CH}_{2}\right.$ linkage), $6.28(\mathrm{~s}, 1 \mathrm{H}, \mathrm{CH}$ of thiazolidinone), 7.35-8.24 (m, 11H, Ar-CH). EI-MS m/z: $531\left(\mathrm{M}^{+}\right)$. Anal. Calcd. for $\mathrm{C}_{27} \mathrm{H}_{25} \mathrm{~N}_{5} \mathrm{O}_{5} \mathrm{~S}: \mathrm{C}, 61.00 ; \mathrm{H}, 4.74 ; \mathrm{N}, 13.17$. Found: C, 61.18; H, 4.73; N, 13.13 .

1-((Dimethylamino) methyl) - 5-nitro-3 - (4- (4-oxo-3-otolylthiazolidin-2-yl)phenylimino) indolin-2-one (16)

Yield $=74 \%$, m.p. $283-284^{\circ} \mathrm{C}$. IR $(\mathrm{KBr}) \mathrm{cm}^{-1}: 3024(\mathrm{Ar}-\mathrm{CH}), 2946$ $\left(\mathrm{CH}_{2}-\mathrm{CH}\right), 1720(\mathrm{C}=0), 1678(\mathrm{C}=\mathrm{N}), 1625(\mathrm{C}=\mathrm{C}), 1542$ and $1334\left(\mathrm{NO}_{2}\right)$. ${ }^{1} \mathrm{H}-\mathrm{NMR}\left(\mathrm{CDCl}_{3}, 500 \mathrm{MHz}\right) \delta \mathrm{ppm}: 2.16\left(\mathrm{~s}, 6 \mathrm{H}, \mathrm{N}\left(\mathrm{CH}_{3}\right)_{2}\right), 2.59(\mathrm{~s}, 3 \mathrm{H}$, $\left.\mathrm{CH}_{3}\right), 3.67$ (s, $2 \mathrm{H}, \mathrm{CH}_{2}$ of thiazolidinone), 4.38 (s, $2 \mathrm{H}, \mathrm{CH}_{2}$ linkage), 5.93 (s, 1H, CH of thiazolidinone), 6.94-8.12 (m, 11H, Ar-CH). EI-MS m/z: 515 $\left(\mathrm{M}^{+}\right)$. Anal. Calcd. for $\mathrm{C}_{27} \mathrm{H}_{25} \mathrm{~N}_{5} \mathrm{O}_{4} \mathrm{~S}: \mathrm{C}, 62.90 ; \mathrm{H}, 4.89 ; \mathrm{N}, 13.58$. Found: $\mathrm{C}$, 63.12; $\mathrm{H}, 4.87 ; \mathrm{N}, 13.56$

1-((Dimethylamino)methyl)-5-nitro-3-(4-(3-(2-nitrophenyl)-4oxothiazolidin-2-yl)phenyl imino)indolin-2-one (17)

Yield $=79 \%$, m.p. $202-204^{\circ} \mathrm{C}$. IR $(\mathrm{KBr}) \mathrm{cm}^{-1}: 3017(\mathrm{Ar}-\mathrm{CH}), 2959$ $\left(\mathrm{CH}_{2}-\mathrm{CH}\right), 1731(\mathrm{C}=0), 1665(\mathrm{C}=\mathrm{N}), 1603(\mathrm{C}=\mathrm{C}), 1537$ and $1352\left(\mathrm{NO}_{2}\right)$. ${ }^{1} \mathrm{H}-\mathrm{NMR}\left(\mathrm{CDCl}_{3}, 500 \mathrm{MHz}\right) \delta \mathrm{ppm}: 2.43\left(\mathrm{~s}, 6 \mathrm{H}, \mathrm{N}\left(\mathrm{CH}_{3}\right)_{2}\right), 3.69(\mathrm{~s}, 2 \mathrm{H}$, $\mathrm{CH}_{2}$ of thiazolidinone), $4.20\left(\mathrm{~s}, 2 \mathrm{H}, \mathrm{CH}_{2}\right.$ linkage), $5.85(\mathrm{~s}, 1 \mathrm{H}, \mathrm{CH}$ of thiazolidinone), 7.07-8.31 (m, 11H, Ar-CH). EI-MS m/z: $546\left(\mathrm{M}^{+}\right)$. Anal. Calcd. for $\mathrm{C}_{26} \mathrm{H}_{22} \mathrm{~N}_{6} \mathrm{O}_{6} \mathrm{~S}$ : C, 57.14; H, 4.06; N, 15.38. Found: C, 57.29; H, $4.07 ; \mathrm{N}, 15.32$.
3-(4-(3-(2-Chlorophenyl)-4-oxothiazolidin-2-yl)phenylimino)-1((dimethylamino)methyl)-5-nitroindolin-2-one (18)

Yield $=77 \%$, m.p. $279-280^{\circ} \mathrm{C}$. IR (KBr) cm${ }^{-1}: 3001(\mathrm{Ar}-\mathrm{CH}), 2925\left(\mathrm{CH}_{2}-\right.$ $\mathrm{CH}), 1713(\mathrm{C}=\mathrm{O}), 1657(\mathrm{C}=\mathrm{N}), 1622(\mathrm{C}=\mathrm{C}), 1558$ and $1320\left(\mathrm{NO}_{2}\right), 782$ (C-Cl). ${ }^{1} \mathrm{H}-\mathrm{NMR}\left(\mathrm{CDCl}_{3}, 500 \mathrm{MHz}\right) \delta \mathrm{ppm}: 2.34\left(\mathrm{~s}, 6 \mathrm{H}, \mathrm{N}\left(\mathrm{CH}_{3}\right)_{2}\right), 3.35$ (s, $2 \mathrm{H}, \mathrm{CH}_{2}$ of thiazolidinone), $4.13\left(\mathrm{~s}, 2 \mathrm{H}, \mathrm{CH}_{2}\right.$ linkage), $6.26(\mathrm{~s}, 1 \mathrm{H}, \mathrm{CH}$ of thiazolidinone), 7.11-8.00 (m, 11H, Ar-CH). EI-MS m/z: $535\left(\mathrm{M}^{+}\right)$. Anal. Calcd. for $\mathrm{C}_{26} \mathrm{H}_{22} \mathrm{ClN}_{5} \mathrm{O}_{4} \mathrm{~S}$ : C, 58.26; $\mathrm{H}, 4.14 ; \mathrm{N}, 13.07$. Found: C, 58.13; H, 4.16; N, 13.12 .

3-(4-(3-(2-Bromophenyl)-4-oxothiazolidin-2-yl)phenylimino)-1((dimethylamino) methyl)-5-nitroindolin-2-one (19)

Yield $=80 \%$, m.p. $246-248^{\circ} \mathrm{C}$. IR (KBr) cm${ }^{-1}: 3008(\mathrm{Ar}-\mathrm{CH}), 2942\left(\mathrm{CH}_{2}{ }^{-}\right.$ $\mathrm{CH}), 1720(\mathrm{C}=0), 1659(\mathrm{C}=\mathrm{N}), 1617(\mathrm{C}=\mathrm{C}), 1545$ and $1344\left(\mathrm{NO}_{2}\right), 687$ (C-Br). ${ }^{1} \mathrm{H}-\mathrm{NMR}\left(\mathrm{CDCl}_{3}, 500 \mathrm{MHz}\right) \delta \mathrm{ppm}: 2.19\left(\mathrm{~s}, 6 \mathrm{H}, \mathrm{N}\left(\mathrm{CH}_{3}\right)_{2}\right), 3.53$ (s, $2 \mathrm{H}, \mathrm{CH}_{2}$ of thiazolidinone), $4.12\left(\mathrm{~s}, 2 \mathrm{H}, \mathrm{CH}_{2}\right.$ linkage), $6.04(\mathrm{~s}, 1 \mathrm{H}, \mathrm{CH}$ of thiazolidinone), 6.86-7.75 (m, 11H, Ar-CH). EI-MS m/z: 579 (M+). Anal. Calcd. for $\mathrm{C}_{26} \mathrm{H}_{22} \mathrm{BrN}_{5} \mathrm{O}_{4} \mathrm{~S}: \mathrm{C}, 53.80 ; \mathrm{H}, 3.82 ; \mathrm{N}, 12.07$. Found: C, 53.97; $\mathrm{H}$, 3.81; N, 12.03 .

\section{Biological activities}

Antitubercular activity

Antitubercular potency of title compounds was estimated by agar dilution method (In vitro M. tuberculosis method) [34,35]. Using OADC growth supplement in Middlebrook 7H11 Agar, slants each test analogs were incorporated in 10 -fold serial dilutions. M. tuberculosis $\mathrm{H}_{37} \mathrm{RV}$ inoculums were prepared using OADC growth supplement in fresh Middlebrook 7H11 Agar slants adjusted to $1 \mathrm{mg} / \mathrm{ml}$ in $0.05 \%$ tween 80 saline diluted to $10^{-2}\left(10^{7} \mathrm{CFU} / \mathrm{ml}\right.$ concentration approximately). In 7H11 agar tubes per ml 10-fold serial dilutions of test analogs, $5 \mu \mathrm{l}$ bacterial suspensions were added. At $37^{\circ} \mathrm{C}$ incubated the tubes and after 28 days, final readings were measured. Results obtained on test tubes (Test analog, medium and $\mathrm{H}_{37} \mathrm{RV}$ ) were compared with control tubes (Medium and $\mathrm{H}_{37} \mathrm{RV}$ ). The concentration at which complete inhibition of $M$. tuberculosis growth occurs is known as minimum inhibitory concentration (MIC). INH (Isoniazid) was used as standard drug for comparing MIC of the title analogs and the obtained results are depicted in Table1.

\section{Antimicrobial activity}

Agar streak dilution method was used to study antimicrobial potency of test analogs. Against four Gram-positive bacteria (Bacillus cereus ATCC 11778, Micrococcus luteus ATCC 4698, Staphylococcus epidermidis ATCC 155, and Staphylococcus aureus ATCC 9144) and three Gram-negative bacteria (Klebsiella pneumoniae ATCC 11298, Pseudomonas aeruginosa ATCC 2853, and Escherichia coli ATCC 25922) synthesized compounds were screened for antibacterial activity. In addition against two fungi (Aspergillus fumigatus ATCC 46645 and Aspergillus niger ATCC 9029) synthesized analogs were tested for antifungal potency. For antibacterial activity, at $37^{\circ} \mathrm{C}$ various bacterial strains were cultured in Mueller-Hinton broth overnight. Likewise, for antifungal activity, at $30^{\circ} \mathrm{C}$, various fungal strains were cultured in YEPDE agar overnight. The final densities of test strains were made to $5 \times 10^{-5} \mathrm{CFU} / \mathrm{ml}$ using nutrient agar medium.

\section{MIC}

Agar streak dilution method was used to find out the MIC of test analogs [36]. DMF was used to prepare a stock solution of test analogs. In specified quantity of molten sterile agar (nutrient agar for antibacterial activity and Sabouraud's Dextrose Agar medium for antifungal activity) graded quantities of the synthesized analogs were incorporated. In Petri dish at $40-50^{\circ} \mathrm{C}$, a specified quantity of test analogs incorporated medium was poured and allowed to solidify to give a 3-4 mm depth. Latter to the plates containing test analogs (in DMF) and medium, microbial suspension $\left(5 \times 10^{-5} \mathrm{CFU} / \mathrm{ml}\right)$ were applied. Finally, Petri plates were incubated at $37^{\circ} \mathrm{C}$ for $24 \mathrm{~h}$ and $48 \mathrm{~h}$ for bacteria and fungi, respectively. The lowest concentration at which no visible growth of bacteria or fungi is considered as MIC and the found MIC of test analogs and the standard drug is shown in Table 1. 


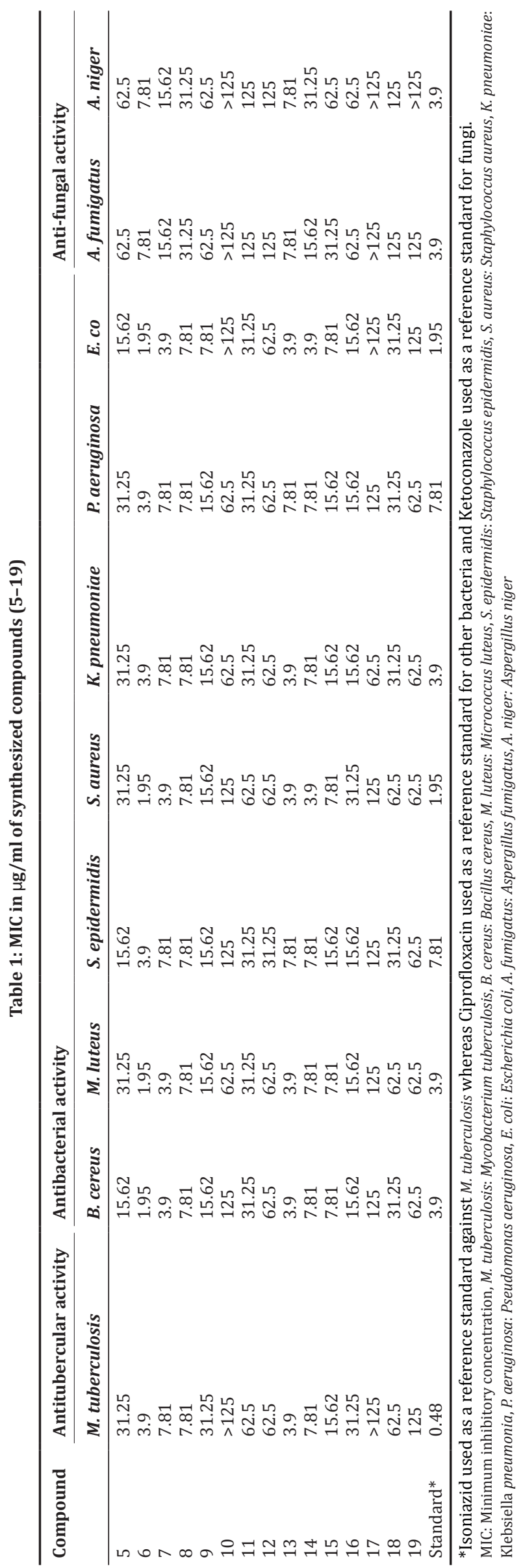

\section{RESULTS AND DISCUSSION}

\section{Chemistry}

Title compounds 5-19 were synthesized as per the protocol mentioned in Scheme 1. By substituting different thiazolidinone moiety at C-3 and (dimethylamino)methyl moiety at $\mathrm{C}-1$ of 5-nitroisatin, a series of novel Schiff and Mannich bases of 5-nitroisatin analogs 5-19 were synthesized in this work. A sequence of novel 1-((dimethylamino) methyl)-3-(4-(3-(substituted phenyl)-4-oxothiazolidin-2-yl) phenylimino)-5-nitroindolin-2-one derivatives 5-19 were prepared from isatin using a multistep synthesis. Initially, isatin one was nitrated using nitrating mixture (sulfuric acid and nitric acid) to obtain 5-nitro isatin 2 . In the next step 5-nitro isatin 2 was treated with p-amino benzaldehyde and glacial acetic acid (catalyst) in ethanol to produce 4-(5-nitro-2-oxoindolin-3-ylideneamino)benzaldehyde 3 by Schiff base mechanism with the removal of one water molecule. In the succeeding step compound 3 underwent Mannich reaction with dimethylamine and formaldehyde to produce 4-(1-((dimethylamino)methyl)-5nitro-2-oxoindolin-3-ylideneamino)benzaldehyde 4 with loss of one water molecule. In the final step by treating 4-(1-((dimethylamino) methyl)-5-nitro-2-oxoindolin-3-ylideneamino)benzaldehyde 4 with mercaptoacetic acid and various arylamine through cyclization reaction title compounds 5-19 were synthesized. Ring closure takes place with a loss of two water molecules. The reaction optimization, completion, and purity of the synthesized intermediates and final compounds are confirmed by TLC.

IR, ${ }^{1} \mathrm{H}-\mathrm{NMR}$, mass spectra, and elemental analyses data are used to confirm the structures of synthesized novel 5-nitroisatin analogs 5-19. All spectral data are in accordance with the assigned structures. The presence of specific groups in compounds is represented in IR spectra by some characteristic absorption peaks. In IR spectrum appearance of a peak at 1546 and $1328 \mathrm{~cm}^{-1}$ corresponding to aromatic nitro group confirms the formation of 5-nitroisatin 2. Likewise, in IR spectrum appearance of stretching vibration for $\mathrm{C}=\mathrm{N}$ at $1669 \mathrm{~cm}^{-1}$ and in NMR spectrum a singlet peak for aldehyde proton at $\delta 10.13 \mathrm{ppm}$ confirms the assigned structure of 4-(5-nitro-2-oxoindolin-3-ylideneamino) benzaldehyde 3. The compound 4 formed through Mannich reaction was confirmed by the absence of absorption bands around $3350 \mathrm{~cm}^{-1}$ corresponds to NH stretching and appearance of a peak at $2944 \mathrm{~cm}^{-1}$ corresponds to $\mathrm{CH}_{3}-\mathrm{CH}$ stretching in its IR spectrum. It is further supported by ${ }^{1} \mathrm{H}-\mathrm{NMR}$ spectrum in which singlet appeared at $\delta 4.32 \mathrm{ppm}$ for two protons of $\mathrm{CH}_{2}$ linkage and another singlet appeared for six protons of dimethylamino group at $\delta 2.17 \mathrm{ppm}$. Title compounds show absorption bands in IR spectrum at 3001-3029 $\mathrm{cm}^{-1}, 2924-2959 \mathrm{~cm}^{-1}$, $1713-1738 \mathrm{~cm}^{-1}, 1650-1678 \mathrm{~cm}^{-1}$, and $1603-1629 \mathrm{~cm}^{-1}$, which can be assignable to $\mathrm{Ar}-\mathrm{H}, \mathrm{CH}_{3}-\mathrm{CH}, \mathrm{C}=\mathrm{O}, \mathrm{C}=\mathrm{N}$, and $\mathrm{C}=\mathrm{C}$ vibrations, respectively. In addition, nitro group present in title compounds is confirmed by the appearance of two characteristic peaks in IR at 1524-1558 $\mathrm{cm}^{-1}$, and $1312-1354 \mathrm{~cm}^{-1}$. The below-mentioned conclusions were made after observing the ${ }^{1} \mathrm{H}$-NMR spectra of novel synthesized compounds $5-19$. The presence of dimethylamino moiety was evidenced by the appearance of singlet for six protons at $\delta 2.16-2.43 \mathrm{ppm}$. A singlet at $\delta$ 3.30-3.69 ppm for two protons is due to $\mathrm{CH}_{2}$ of thiazolidinone. The appearance of singlet for two protons at $\delta 4.04-4.38 \mathrm{ppm}$ confirms the presence of $\mathrm{CH}_{2}$ linkage. $\mathrm{CH}$ of thiazolidinone was evidenced by appearance of one proton singlet at $\delta 5.80-6.28 \mathrm{ppm}$. A group of signals (multiplet) appeared between $\delta 6.80$ and $8.31 \mathrm{ppm}$ corresponds to $\mathrm{Ar}-\mathrm{H}$ protons. Further mass spectrum confirmed their purity and molecular weight.

\section{Biological activities}

Antitubercular activity

In vitro antitubercular activity of all title analogs was screened against $M$. tuberculosis $\left(\mathrm{H}_{37} \mathrm{Rv}\right.$ strain) and MIC of entire tested analogs was determined and presented in Table 1 and Fig. 1. Simultaneously, MIC of INH was also measured to control the sensitivity of the test organisms. From the results, it was found that in varying degree synthesized compounds inhibited the growth of M. tuberculosis. 


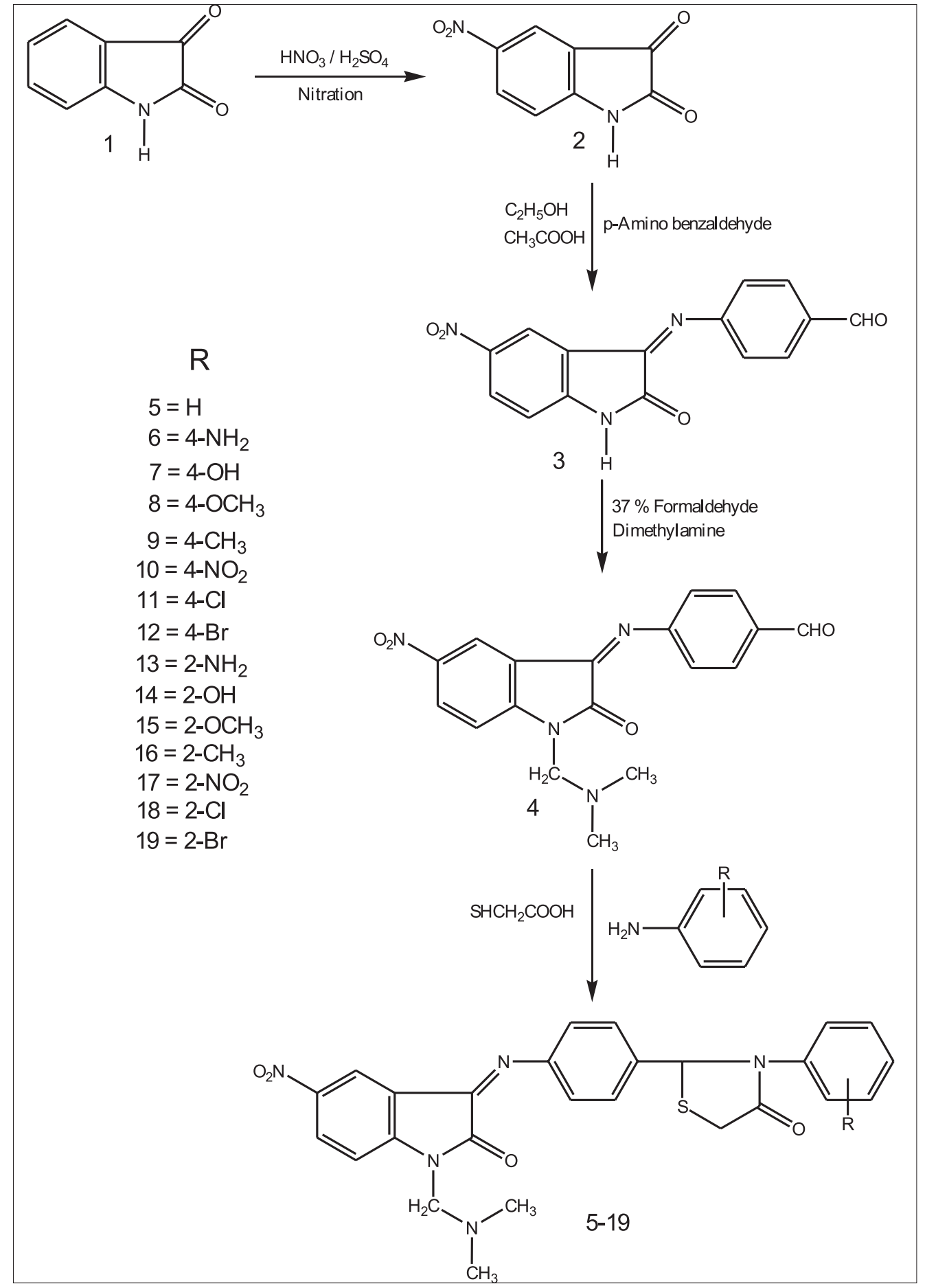

Scheme 1: Synthetic protocols of intermediates and title compounds (5-19)

Among various tested compounds, analogs such as 6 and 13 inhibited the growth of M. tuberculosis at a low concentration (MIC: $3.9 \mu \mathrm{g} / \mathrm{ml}$ ). Both derivatives possess amino moiety at phenyl ring attached to thiazolidinone ring. MIC of test compounds 7, 8, and 14 was found to be $7.81 \mu \mathrm{g} / \mathrm{ml}$ may be due to the presence of hydroxy and methoxy substituent in phenyl ring. In addition, derivative 15 containing methoxy moiety completely inhibited the growth of M. tuberculosis at $15.62 \mu \mathrm{g} / \mathrm{ml}$ concentration. The MIC of analogs 5,9 , and 16 was found to be $31.25 \mu \mathrm{g} / \mathrm{ml}$ and test compounds 11,12 , and 18 were found to be $62.5 \mu \mathrm{g} / \mathrm{ml}$. Only at higher concentration remaining synthesized derivatives (compounds 10,17, and 19) displayed activity (MIC: $\geq 125 \mu \mathrm{g} / \mathrm{ml}$ ).

\section{Antimicrobial activity}

In vitro, agar streak dilution method was employed to screen the antimicrobial activity of test derivatives 5-19. Simultaneously, MIC of ciprofloxacin and ketoconazole was also measured to control the sensitivity of the test organisms. The MIC of standard and test analogs was compared effectively in Table 1 and Figs. 2-4.

Antimicrobial data indicate that test analog 6 (MIC: $1.95 \mu \mathrm{g} / \mathrm{ml}$ ) exhibited superior activity than ciprofloxacin against $B$. cereus; whereas test analogs 7 and 13 (MIC: $3.9 \mu \mathrm{g} / \mathrm{ml}$ ) exhibited similar activity and remaining analogs displayed inferior activity (MIC: $\geq 7.81 \mu \mathrm{g} / \mathrm{ml}$ ). Compared to ciprofloxacin against M. luteus derivative 6 showed higher 


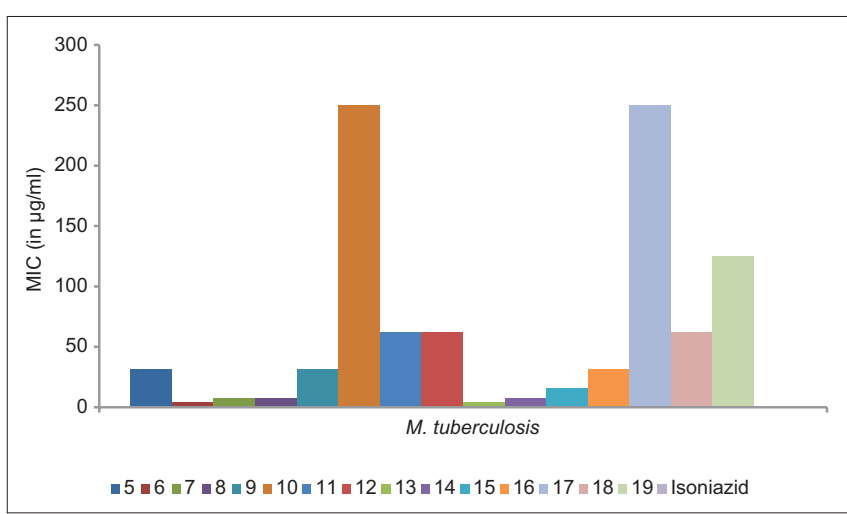

Fig. 1: Minimum inhibitory concentration in $\mu \mathrm{g} / \mathrm{ml}$ of synthesized compounds (5-19) against Mycobacterium tuberculosis

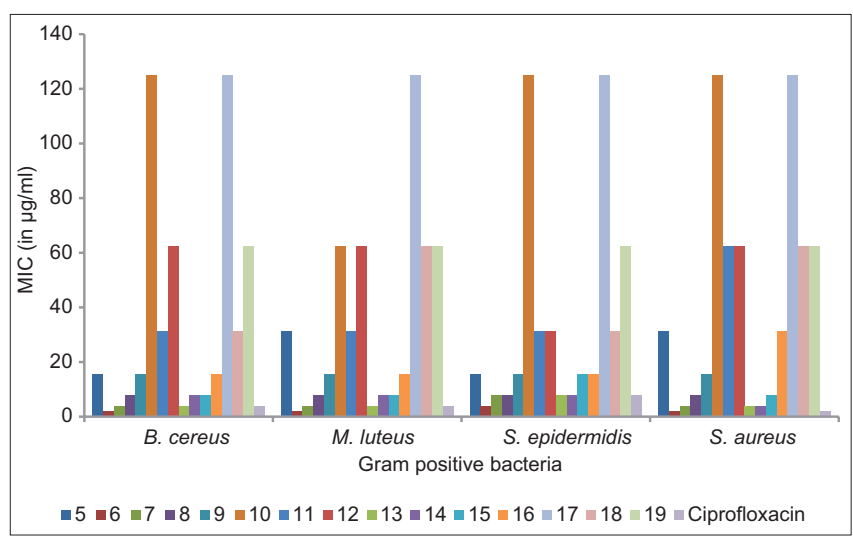

Fig. 2: Minimum inhibitory concentration in $\mu \mathrm{g} / \mathrm{ml}$ of synthesized compounds (5-19) against various Gram-positive bacteria

activity (MIC: $1.95 \mu \mathrm{g} / \mathrm{ml}$ ) and derivatives 7 and 13 (MIC: $3.9 \mu \mathrm{g} / \mathrm{ml}$ ) showed equal activity; whereas other tested derivatives showed lesser activity (MIC: $\geq 7.81 \mu \mathrm{g} / \mathrm{ml}$ ). Against $S$. epidermidis test compound 6 exhibited greater activity (MIC: $3.9 \mu \mathrm{g} / \mathrm{ml}$ ) compared to ciprofloxacin and compounds 7, 8, 13, and 14 displayed identical activity (MIC: $7.81 \mu \mathrm{g} / \mathrm{ml}$ ); whereas leftover compounds produced subordinate activity (MIC: $\geq 15.62 \mu \mathrm{g} / \mathrm{ml}$ ). Compound 6 (MIC: $1.95 \mu \mathrm{g} / \mathrm{ml}$ ) exhibited similar activity like ciprofloxacin against $S$. aureus; whereas residual analog displayed inferior activity (MIC: $\geq 3.9 \mu \mathrm{g} / \mathrm{ml}$ ). While the rest of analogs exhibited weaker activity (MIC: $\geq 7.81 \mu \mathrm{g} / \mathrm{ml}$ ) than ciprofloxacin against K. pneumoniae, tested derivatives 6 and 13 showed alike activity (MIC: $3.9 \mu \mathrm{g} / \mathrm{ml}$ ). Against P. aeruginosa compound 6 exhibited better activity (MIC: $3.9 \mu \mathrm{g} / \mathrm{ml}$ ) than ciprofloxacin and test compounds 7, 8, 13, and 14 displayed the similar activity (MIC: $7.81 \mu \mathrm{g} / \mathrm{ml}$ ); while rest of entire analogs displayed worser activity (MIC: $\geq 15.62 \mu \mathrm{g} / \mathrm{ml}$ ). Compound 6 showed alike potency (MIC: $1.95 \mu \mathrm{g} / \mathrm{ml}$ ) as ciprofloxacin, whereas remaining analogs exhibited inferior activity (MIC: $\geq 3.9 \mu \mathrm{g} / \mathrm{ml}$ ) than ciprofloxacin against E. coli. Out of 15 tested compounds, compound 6 displayed higher activity against all tested Gram-positive and Gramnegative bacteria than the rest of tested compounds.

Against A. fumigatus and A. niger synthesized compounds were screened for its antifungal activity and found to display a varying degree of antifungal potency. None of the tested analogs displayed superior or equal activity compared to Ketoconazole against both tested fungi (A. fumigatus and A. niger). Out of various tested analogs, compounds 6 and 13 were found to be the most potent compounds of this series. From the study, in general, it was found that compounds 6-8 and 13-15 displayed good antimicrobial activity; compounds 5, 9, and 16 exhibited moderate antimicrobial activity; whereas rest of title compounds (10-12 and 17-19) displayed poor antimicrobial activity.

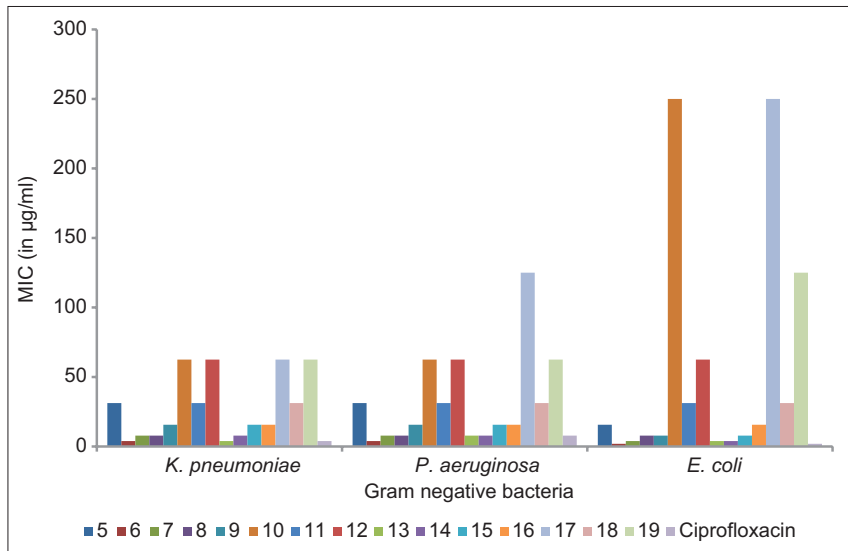

Fig. 3: Minimum inhibitory concentration in $\mu \mathrm{g} / \mathrm{ml}$ of synthesized compounds (5-19) against various Gram-negative bacteria

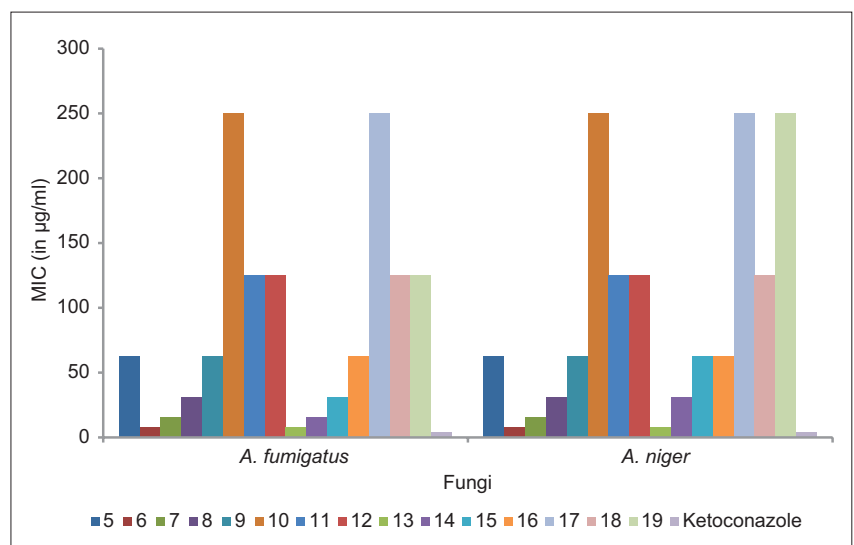

Fig. 4: Minimum inhibitory concentration in $\mu \mathrm{g} / \mathrm{ml}$ of synthesized compounds (5-19) against various fungi

\section{Structural activity relationship}

SAR of synthesized compounds is depicted in Fig. 5. In this study, overall it was found that title analogs 6-8 and 13-15 exhibited good antimicrobial activity; title analogs 5, 9, and 16 showed moderate antimicrobial activity; whereas all other title analogs (10-12 and 17-19) produced only reduced antimicrobial activity. In phenyl ring attached to thiazolidinone ring, the presence of electron donating substituent such as amino, hydroxy, and methoxy moiety might be responsible for thepowerfulantibacterial activity displayed by derivatives 6-8 and 13-15. In general, from the SAR study, it was found that isatin derivatives possessing electron releasing group 6-8 and 13-15 exhibited superior antimicrobial potency than corresponding isatin derivatives possessing electron withdrawing moieties 9-12 and 16-19 while unsubstituted analogs displayed intermediate activity. In addition, it was also found that position of the substituent does not play any important role in antimicrobial activity because ortho substituted analogs 13-19 showed almost equal activity to corresponding para substituted analogs 6-12. Moreover, test compounds displayed better activity against tested bacteria than fungi. Out of 15 title compounds, the potent compounds were found to be 3-(4-(3-(4-aminophenyl)4-oxothiazolidin-2-yl)phenylimino)-1-((dimethylamino)methyl)-5nitroindolin-2-one 6 and 3-(4-(3-(2-aminophenyl)-4-oxothiazolidin-2-yl) phenylimino)-1-((dimethylamino)methyl)-5-nitroindolin-2-one 13.

\section{CONCLUSION}

In summing up, from isatin using multistep synthesis various novel Schiff and Mannich bases of 5-nitroisatin was synthesized by substituting different 3-(substitutedphenyl)-2- phenylimino thiazolidinone moiety at C-3 and (dimethylamino)methyl moiety at C-1 of 5-nitroisatin. FTIR, ${ }^{1} \mathrm{H}-\mathrm{NMR}$, Mass spectroscopy, and elemental analysis are used to 


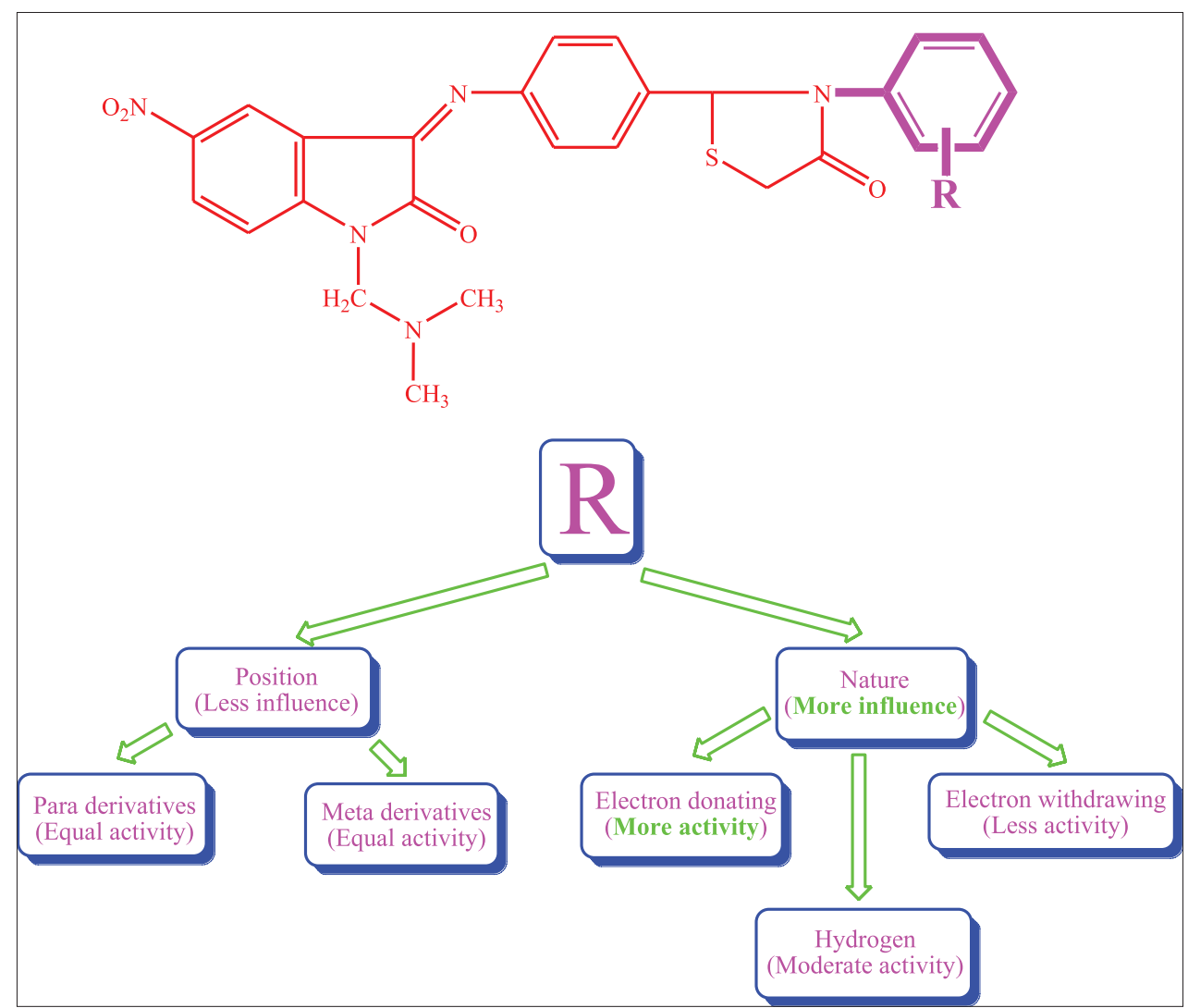

Fig. 5: SAR of novel Schiff and Mannich bases of 5-nitroisatin (5-19)

confirm the chemical structure of all synthesized intermediate and title derivatives. In vitro antitubercular, antibacterial, and antifungal activities of all novel analogs were estimated by measuring its MIC. This series of analogs displayed a varying degree of antimicrobial activity (mild to good). SAR studies revealed that in determining the antimicrobial activity of novel 5-nitroisatins nature of substituent played a major role than the position of the substituent. Isatin derivatives possessing electron releasing group exhibited superior antimicrobial potency than corresponding isatin derivatives possessing electron withdrawing moieties while unsubstituted analogs displayed intermediate activity. Out of several 5-nitroisatins tested in this series, the potent antibacterial compounds were found to be 3-(4-(3-(4-aminophenyl)4-oxothiazolidin-2-yl)phenylimino)-1-((dimethylamino)methyl)-5nitroindolin-2-one 6 and 3-(4-(3-(2-aminophenyl)-4-oxothiazolidin2-yl)phenylimino)-1-((dimethylamino)methyl)-5-nitroindolin-2-one 13. These derivatives displayed potent antibacterial activity which is greater than or almost equal to the tested reference drug. In addition, derivatives 6 and 13 also exhibited some notable antifungal activity against tested fungi. Moreover, these analogs also showed good antitubercular activity. For this reason, these compounds might be extended as a novel class of antimicrobial agents. On the other hand, to enhance the anti-tubercular and antibacterial activity further structural modification is planned.

\section{ACKNOWLEDGMENTS}

Authors are thankful to the management of MNR College of Pharmacy, Fasalwadi, Sangareddy-502294, Telangana, India, and GITAM - Deemed to be University, Gandhi Nagar, Rushikonda, Visakhapatnam-530 045, Andhra Pradesh, India for providing necessary facilities to carry out the research work successfully.

\section{AUTHORS' CONTRIBUTIONS}

KL designed and performed experiments. She was involved in manuscript editing and finalization as well. RS designed entire study project contributed in experiment finalization and implementation, manuscript editing, and finalization.

\section{CONFLICTS OF INTEREST}

The authors declare that they have no conflicts of interest.

\section{REFERENCES}

1. Halezeroğlu S, Okur E. Thoracic surgery for haemoptysis in the context of tuberculosis: What is the best management approach? J Thorac Dis 2014;6:182-5

2. Golden MP, Vikram HR. Extrapulmonary tuberculosis: An overview. Am Fam Physician 2005;72:1761-8.

3. Klemens SP, DeStefano MS, Cynamon MH. Therapy of multidrugresistant tuberculosis: Lessons from studies with mice. Antimicrob Agents Chemother 1993;37:2344-7.

4. Maste MM, Jeyarani P, Kalekar MC, Bhat AR. Synthesis and evaluation of benzimidazole derivatives for anti-tubercular and anti-microbial activities. Asian J Res Chem 2011;4:1055-8.

5. Parish T, Stoker NG. Mycobacteria: Bugs and bugbears (two steps forward and one step back). Mol Biotechnol 1999;13:191-200.

6. Zumla A, Nahid P, Cole ST. Advances in the development of new tuberculosis drugs and treatment regimens. Nat Rev Drug Discov 2013;12:388-404.

7. Klopper M, Warren RM, Hayes C, Gey van Pittius NC, Streicher EM, Müller B, et al. Emergence and spread of extensively and totally drugresistant tuberculosis, South Africa. Emerg Infect Dis 2013;19:449-55.

8. Slomski A. South Africa warns of emergence of "totally" drug-resistant tuberculosis. J Am Med Assoc 2013;309:1097-8.

9. Prasad R. Management of multi-drug resistant tuberculosis: Practitioner's view point. Indian J Tuberc 2007;54:3-11

10. Saravanan G, Alagarsamy V, Kumar PD, Selvam TP, Prakash CR. Isatin-a potent anticonvulsant agent. Eur J Biomed Pharm Sci 2017:4:277-82.

11. Chinnasamy RP, Sundararajan R, Govidaraj S. Synthesis, analgesic, anti-inflammatory and in vitro antimicrobial studies of some novel Schiff and mannich base of 5 -substituted isatin derivatives. Int J Pharm Pharm Sci 2014;6:160-6.

12. Penthala NR, Yerramreddy TR, Madadi NR, Crooks PA. Synthesis 
and in vitro evaluation of $\mathrm{N}$-alkyl-3-hydroxy-3-(2-imino-3-methyl-5oxoimidazolidin-4-yl)indolin-2-one analogs as potential anticancer agents. Bioorg Med Chem Lett 2010;20:4468-71.

13. Prakash CR, Raja S, Saravanan G. Synthesis and anti-epileptic activity of some novel 3-(4-(4-(substitutedbenzylideneamino)-5-mercapto4-1,2,4-triazole-3-yl)phenylimino)-1- ((dimethylamino)methyl)-5fluoroindolin-2-one derivatives. Int J Pharm Pharm Sci 2014;6:539-44.

14. Selvam P, Chandramohan M, De Clercq E, Witvrouw M, Pannecouque C. Synthesis and anti-HIV activity of 4-[(1,2-dihydro-2-oxo-3H-indol-3ylidene) amino]-N(4,6-dimethyl-2-pyrimidinyl)-benzene sulfonamide and its derivatives. Eur J Pharm Sci 2001;14:313-6.

15. Saravanan G, Alagarsamy V, Dineshkumar P. Anticonvulsant activity of novel 1-(morpholinomethyl)-3-substituted isatin derivatives. Bull Fac Pharm (Cairo Univ) 2014;52:115-24.

16. Karthik K, Priyanka KB, Manjula S, Sammaiah G. Synthesis and evaluation of new bis-isatin derivatives for antioxidant activity. Int $\mathrm{J}$ Pharm Pharm Sci 2013;5:224-7.

17. González A, Quirante J, Nieto J, Almeida MR, Saraiva MJ, Planas A, et al. Isatin derivatives, a novel class of transthyretin fibrillogenesis inhibitors. Bioorg Med Chem Lett 2009;19:5270-3.

18. Chinnasamy RP, Sundararajan R, Govindaraj S. Synthesis, characterization and anti-convulsant activity of novel Schiff base of isatin derivatives. Int J Pharm Pharm Sci 2010;2:177-81.

19. Ahmed MN, Hassan MA, Mashooq AB, Mohamed AA, Abd EG. Microwave-assisted synthesis and anti-microbial activity of some novel isatin Schiff bases linked to nicotinic acid via certain amino acid bridge. J Chem 2015;364841:1-8.

20. Amani AM. Synthesis, characterization and biological activities of some novel isatin derivatives. Bulg Chem Commun 2014;46:795-800.

21. Brkić DR, Božić AR, Marinković AD, Milčić MK, Prlainović NŽ Assaleh FH, et al. Detailed solvent, structural, quantum chemical study and antimicrobial activity of isatin schiff base. Spectrochim Acta A Mol Biomol Spectrosc 2018;196:16-30.

22. Kalawati M, Sudesh K, Jitender MK, Amita M, Chetan S, Harsh P. One pot three component synthesis of spiro[indolo-3,10'-indeno[1,2-b] quinolin]-2,4,11'-triones as a new class of anti-fungall and antimicrobial agents. Chin Chem Lett 2017;28:136-42.

23. Mahmoud FA, Wagdy ME, Riham FG, Marwa MA, Mahmoud ME, Nagwa MA, et al. Novel indole-thiazolidinone conjugates: Design, synthesis and whole-cell phenotypic evaluation as a novel class of antimicrobial agents. Eur J Med Chem 2018;160:49-60.

24. Prakash CR, Raja S, Selvam TP, Saravanan G, Karthick V, Kumar PD. Synthesis and anti-microbial activities of some novel Schiff bases of 5-substituted isatin derivatives. Rasayan J Chem 2009;2:960-8.

25. Rani PJ, Pandiyan MS, Selvi AS, Aruna A, Venkatesan N. Synthesis, characterization and anti-microbial activity of Schiff and mannich bases of isatin derivatives. World J Pharm Pharm Sci 2017;6:1259-67.

26. Prakash C, Raja S, Saravanan G. Synthesis, analgesic, antiinflammatory and in vitro antimicrobial studies of some novel Schiff and mannich base of 5-substituted isatin derivatives. Int J Pharm Pharm Sci 2014;10:160-6.

27. Al-Mudhafar MM. Synthesis, characterization and preliminary antimicrobial evaluation of new Schiff bases of ampicillin and amoxicillin derived from isatin derivatives. Int J Pharm Pharm Sci 2016;5:113-6

28. Metwally NH, Radwan IT, El-Serwy WS, Mohamed MA. Design, synthesis, DNA assessment and molecular docking study of novel 2-(pyridin-2-ylimino)thiazolidin-4-one derivatives as potent antifungal agents. Bioorg Chem 2019;84:456-67.

29. Gawronska-Grzywacz M, Popiołek L, Natorska-Chomicka D, Piątkowska-Chmiel I, Izdebska M, Herbet $\mathrm{M}$, et al. Novel 2,3disubstituted 1,3thiazolidin4one derivatives as potential antitumor agents in renal cell adenocarcinoma. Oncol Rep 2019;41:693-701.

30. Bhutani R, Pathak DP, Kapoor G, Husain A, Iqbal MA. Novel hybrids of benzothiazole-1,3,4-oxadiazole-4-thiazolidinone: Synthesis, in silico ADME study, molecular docking and in vivo anti-diabetic assessment. Bioorg Chem 2019;83:6-19.

31. Abo-Ashour MF, Eldehna WM, George RF, Abdel-Aziz MM, Elaasser MM, Abdel Gawad NM, et al. Novel indole-thiazolidinone conjugates: Design, synthesis and whole-cell phenotypic evaluation as a novel class of antimicrobial agents. Eur J Med Chem 2018;160:49-60.

32. Fesatidou M, Zagaliotis P, Camoutsis C, Petrou A, Eleftheriou P, Tratrat $\mathrm{C}$, et al. 5-adamantan thiadiazole-based thiazolidinones as antimicrobial agents. Design, synthesis, molecular docking and evaluation. Bioorg Med Chem 2018;26:4664-76.

33. Siddiqui N, Alam MS, Stables JP. Synthesis and anticonvulsant properties of 1-(amino-N-arylmethanethio)-3-(1-substituted benzyl-2, 3-dioxoindolin-5-yl) urea derivatives. Eur J Med Chem 2011;46:2236-42.

34. National Committee for Clinical Laboratory Standards. Antimycobacterial Susceptibility Testing for M. tuberculosis. Proposed Standards $\mathrm{M}_{24}-\mathrm{T}$. Villanova, PA: National Committee for Clinical Laboratory Standards; 1995.

35. Sriram D, Yogeeswari P, Dinakaran M, Thirumurugan R. Antimycobacterial activity of novel 1-(5-cyclobutyl-1,3-oxazol-2yl)-3-(substituted)phenyl/pyridyl thiourea endowed with high activity toward multi drug resistant tuberculosis. J Antimicrob Chemother 2007;59:1194-6.

36. Hawkey PM, Lewis DA. Medical Bacteriology: A Practical Approach. $1^{\text {st }}$ ed. New York: Oxford University Press; 1990. p. 181-94. 